\title{
Harnessing Lightning Using Thundercloud Electrification
}

\author{
${ }^{1}$ Sudagoni Sai Charan, ${ }^{2}$ K. Dharma Reddy, ${ }^{3}$ Gadipelli Rajesh, ${ }^{4} \mathrm{CH}$ V Sheshagiri Rao \\ 1,2,3,4 Department of Electrical and Electronics Engineering, Sreenidhi Institute of Science and \\ Technology, Hyderabad, India. ${ }^{1}$ koolcharan5@gmail.com, ${ }^{2}$ rikkybunny668@gmail.com, \\ 3741raj.123@gmail.com, ${ }^{4}$ chvsheshagiri@sreenidhi.edu.in
}

\begin{abstract}
The world is addicted to power, world cannot survive without power. The major problem for shortage of power is Power crisis and it is the talk of the world today. There have been lots many inventions and discoveries for different ways of generation of electricity using the resources. The major part of electricity is generated from Thermal plant, but the fact is a Thermal plant uses Coal as fuel which is a non-renewable resource for energy. Also a Thermal plant pollutes the environment by releasing smokes and fumes. But our personal view on the matter is that nature offers numerous options for regenerating energy. One such viable option underused by mankind is the power of lightning. This project proposes to harness the energy of a lightning in treating the power crisis and finally making power unavailability a thing of the past.
\end{abstract}

Keywords - Cloud-Ground Lightning(CG), Neon Sign Transformer (NST), Multi Mini Capacitors (MMC's), Sphere Gaps or Spark Gaps (SG)

\section{INTRODUCTION}

In the summer of 2007, an alternative energy company called Alternate Energy Holdings, Inc. (AEHI) tested a method for capturing the energy in lightning bolts. The design for the system had been purchased from an Illinois inventor named Steve LeRoy, who had reportedly been able to power a 60 -watt light bulb for 20 minutes using the energy captured from a small flash of artificial lightning. The method involved a tower, a means of shunting off a large portion of the incoming energy, and a capacitor to store the rest. According to Martin A. Uman, co-director of the Lightning Research Laboratory at the University of Florida and a leading authority on lightning, a single lightning strike, while fast and bright, contains very little energy, and dozens of lightning towers like those used in the system tested by AEHI would be needed to operate five 100-watt light bulbs for the course of a year. When interviewed by The New York Times, he stated that the energy in a thunderstorm is comparable to that of an atomic bomb, but trying to harvest the energy of lightning from the ground is "hopeless"[1].

\section{EXISTING PROPOSALS}

According to the paper "Harnessing Electrical energy from Lightning" by S.Malavika an S.Vishal published under Volume 2,Issue 9,September 2013 at IJAIEM the proposal says that a lightning rod serves as a path of least resistance for the lightning to the ground. This energy is tapped and given to a tesla coil based step down transformer thus the energy is stepped down into smaller voltages. This again is manipulated to the sufficient extent and fed to thousands of turbines. Now a turbine generates upto ten to fifteen times the supply voltage. Thus thousands of turbines can generate a power which is almost equal to the initial power of the lightning[3]. Thus the power of a lightning can be effectively harnessed and utilized for powering up even the entire city. Their major challenges faced in the proposed system are when attempting to harvest energy from lightning is the impossibility of predicting when and where thunderstorms will occur. Even during a storm, it is very difficult to tell where exactly lightning will strike.

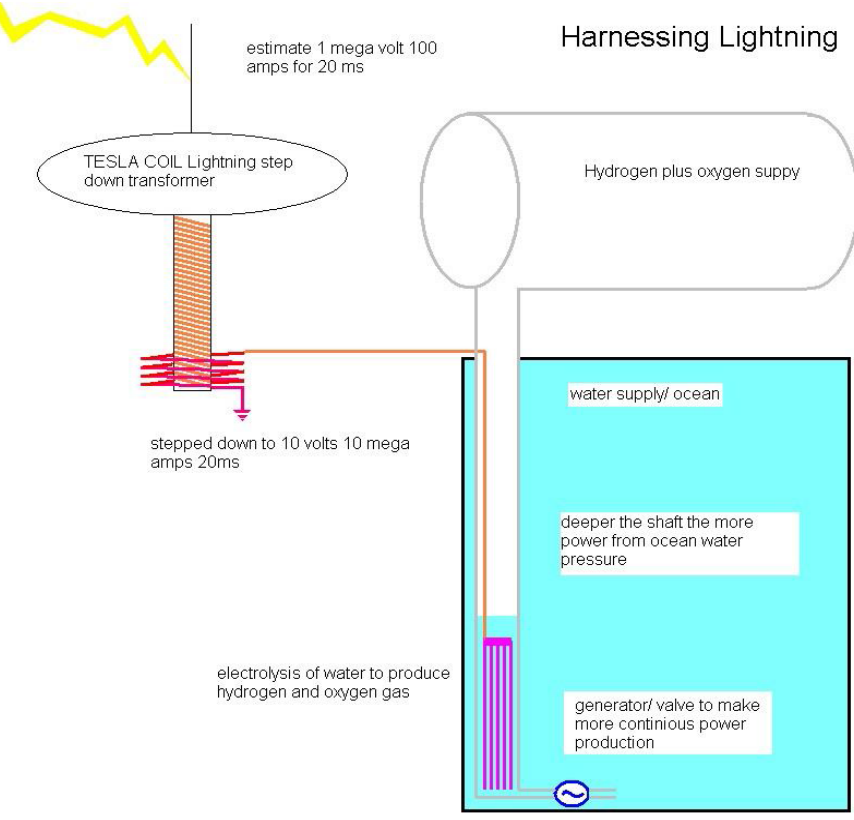

Figure 1 Block Diagram 


\section{THEORY}

a) ELECTRIFICATION OF CLOUD

Cloud-to-ground (CG) lightning is either positive or negative, as defined by the direction of the conventional electric current from cloud to ground. Most CG lightning is negative, meaning that a negative charge is transferred to ground and electrons travel downward along the lightning channel. The reverse happens in a positive CG flash, where electrons travel upward along the lightning channel and a positive charge is transferred to the ground. Positive lightning is less common than negative lightning, and on average makes up less than $5 \%$ of all lightning strikes[4].

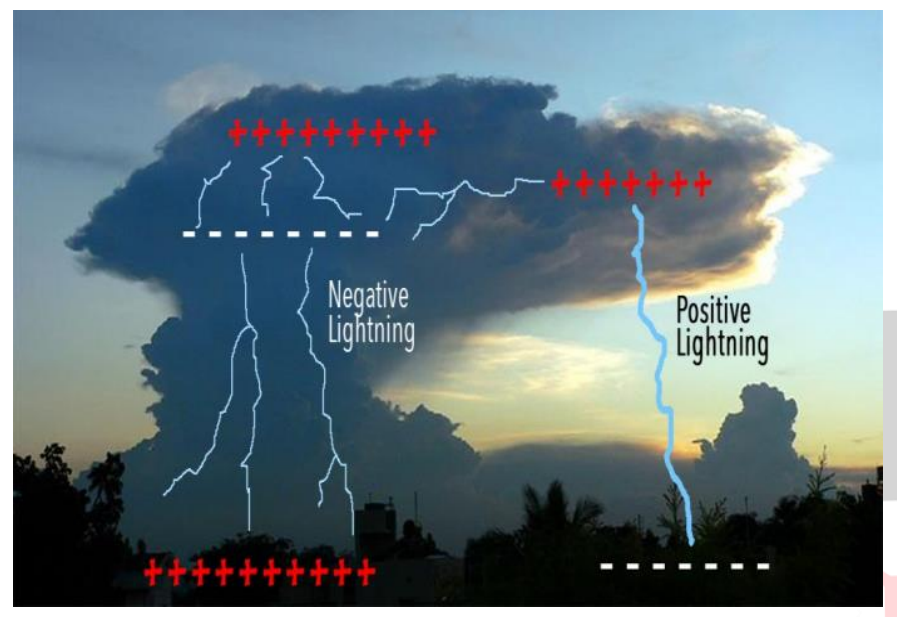

Figure 2 CG Lightning

b) TRIGGERING

We can use artificial triggering methods for capturing of Thunder on the Lightning rod. Basically there exists two type of triggering methods Rocket Triggering and Laser Triggering. Martin. A Uman and his team of scientist started making their own thunder bolts by triggering a rocket into the heart of the thundercloud. His team attached a 6-feet tall rocket to 2300 foot copper spool(winding) which is grounded at one end, this provides the path for the negative charge to hit the ground[5].

\section{c) USE OF ELECTROCERAMICS}

The existing proposal says that a conductor is bonded in between the step down tesla transformer and water body. The problem with this system is the as the conductor carries charge the water gets ionized and thus water starts conducting. The ionized steam can destroy the vanes of the Turbine and might decrease the life span of the Turbine. The water body used in this system cannot be recycled or reused unless the water body performs as a Heat Exchanger. The best example for Electroceramics is the ceramic plate used in Hair Straightner. This plate intakes electric charge but releases heat without any ionization.

\section{OUR PROPOSAL}

So by utilising rocket triggering method we can bring down the lightning strike to the desired location. Instead of targeting huge thunderclouds we can trigger small sized thunderclouds for a safer operations. The existing proposal says that a conductor is bonded in between the step down tesla transformer and a water body. The problem with this system is the conductor carries charge so water gets ionized and thus water starts conducting. The ionized steam can destroy the vanes of the Turbine and might decrease the life span of the Turbine. The water body used in this system cannot be recycled or reused unless the water body performs as a Heat Exchanger.

\section{DEVELOPING A TESLA COIL}

As it is impossible to recreate a discharge from thunder we started developing an artificial thunder from a Tesla coil. The Equivalent capacitance for MMC's is given by:

$$
C_{e q=\frac{1}{2 \pi f\left(\frac{V}{I}\right)}}
$$

There will be a bleeder resistor for each capacitor using inorder to discharge the the capacitor. The Resonant frequency for tuning the Tesla Coil is given by:

$$
f=\frac{1}{2 \pi \sqrt{L C}}
$$

$$
\text { (1) }
$$

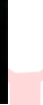

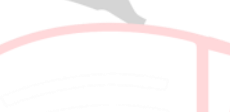




\section{SIMULATION RESULTS}

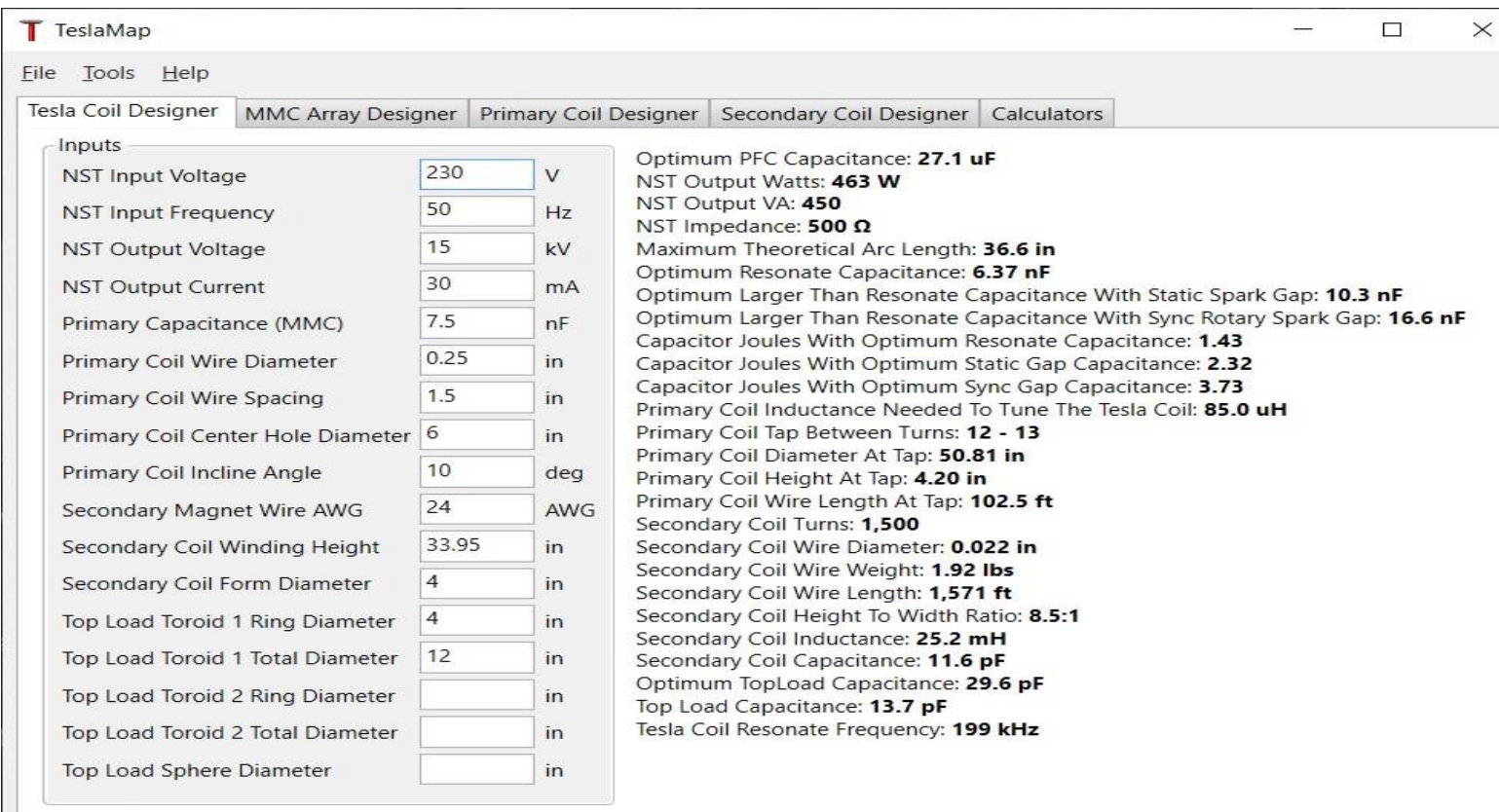

NST Input Voltage: This is the voltage supplied from the wall outlet or variac to the NST low voltage input. Typical values: 120 in N America, 220 in Asia, 230 in Europe.

Figure 3 Designing a Tesla Coil

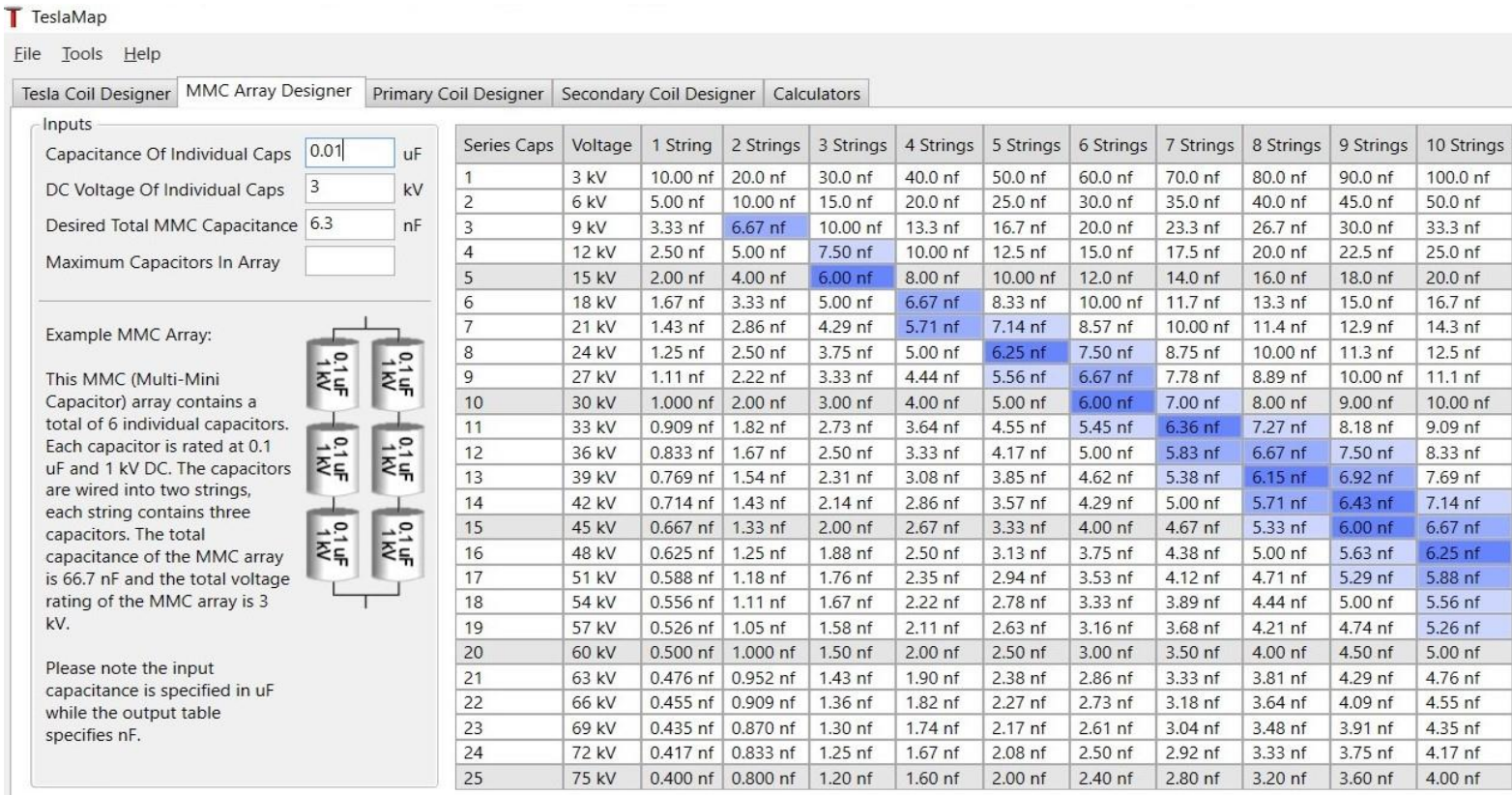

Capacitance Of Individual Caps: This is the capacitance value of a single capacitor in the MMC array (not the total capacitance of the MMC array). Typical values are $0.01 \mathrm{uF}$ to 0.15 uF.

\section{Figure 4 MMC Array Designer}

\section{CONCLUSION}

The equipment used in capturing the lightning strike would have to handle the extreme amount of charge in only around 30 milliseconds (approximate duration of a lighting strike). To handle that kind of instantaneous power, heavy conduction rods are to be used, with ultra-heavy-duty electrical circuits and storage super-capacitors. Although we do not have that technology in electrical energy storage yet, so we proposed a regenerating system using the steam generated from the water body. Capturing lightning is the biggest task but it's done practically by Uman and Team. Similarly, harnessing lightning may seem like a distant dream as of now, but the days are fast approaching when lightning can provide a solution for all our power crisis issues. 


\section{REFERENCES}

[1] Glassie, John (December 9, 2007). "Lightning Farms". The New York Times. Retrieved August 29, 2009.

[2] "Could you power a city with lightning?". physics.org. Retrieved 1 September 2011.

[3] S.Malavika, \& S.Vishal, (2013). Harnessing Electrical Energy from Lightning, volume 2(issue 9), pg 23-27.

[4] "NWS JetStream - The Positive and Negative Side of Lightning". National Oceanic and Atmospheric Administration. Archived from the original on July 5, 2007. Retrieved September 25, 2007.

[5] Neel V. Patel (2015). Don't Try This at Home: Making Lightning Bolts With Rockets, June 24,2015

[6] Kevin Wilson, TeslaMap ver.9.0.4 June,2019

[7] Uman, Martin A.' "All About Lightning"; Ch. 8; p. 68, Dover Publications N.Y.; 1986; ISBN- 2-486-25237-x

[8] Uman, Martin A.' "All About Lightning"; Ch. 6, p. 47, Dover Publications N.Y.; 1986; ISBN- 2-486-25237-X

[9] Tom Hartsfield (2012), Could We Harness Lightning as an Energy Source? May 07, 2012 